Brit. J. prev. soc. Med. (1975), 29, 73-81

\title{
Bladder cancer mortality in diabetics in relation to saccharin consumption and smoking habits
}

\author{
BRUCE ARMSTRONG AND RICHARD DOLL \\ Department of the Regius Professor of Medicine and DHSS Cancer Epidemiology and Clinical Trials Unit, \\ Radcliffe Infirmary, Oxford $O X 26 H E$
}

\begin{abstract}
Armstrong, B. and Doll, R. (1975). British Journal of Preventive and Social Medicine, 29, 73-81 Bladder cancer mortality in diabetics in relation to saccharin consumption and smoking habits. The frequency with which diabetes mellitus was mentioned on the death certificates of 18733 patients dying from bladder cancer has been compared with that of 19709 patients dying from other cancers (excluding cancer of the lung and pancreas). The estimated relative risk of bladder cancer in diabetics was 0.98 with $95 \%$ confidence limits $0 \cdot 70-1 \cdot 38$. There was no increase in risk of bladder cancer in patients with diabetes of long duration. Diabetics were shown by questionnaire to consume substantially more saccharin than non-diabetics, and the duration of regular saccharin use by diabetics was highly correlated with the duration of diabetes. There was therefore no evidence from this study that consumption of above average amounts of saccharin had led to bladder cancer in diabetics. The proportion of current smokers among diabetics was significantly less than among non-diabetics, and this may account for a low relative risk of lung cancer in the former $(0 \cdot 72)$.
\end{abstract}

Animal studies have shown that saccharin consumption may influence the development of cancer of the bladder (Allen et al., 1957; Hicks, Wakefield, and Chowaniec, 1973; BIBRA Information Bulletin, 1973). We therefore examined the trends in saccharin consumption and bladder cancer mortality in England and Wales (Armstrong and Doll, 1974). There was a sharp rise in saccharin consumption with the beginning of the second world war; consumption fell somewhat with the end of sugar rationing in 1953 but has since risen to much higher levels. There was no apparent effect of this rise upon bladder cancer rates, but this did not exclude the possibility of an association in individuals who had consumed large amounts of saccharin. We have, therefore, now studied retrospectively the occurrence of bladder cancer in patients with diabetes mellitus, a group of individuals who consume more than average amounts of saccharin (Beringer, 1973). Kessler (1970) found no increase in bladder cancer mortality in a prospective study of diabetics (21 observed against 29.6 expected), but the period covered (1930-59) may have been too early to observe any effect of saccharin.
We have also documented the saccharin consumption habits of diabetics and obtained data on their use of cigarettes, as cigarette smoking is known to be associated with bladder cancer (Lockwood, 1961; Cole et al., 1971; Doll, 1972).

\section{METHOD}

\section{Bladder Cancer Mortality}

All death certificates assigned to bladder cancer as the underlying cause were scrutinized for any mention of diabetes mellitus in all persons dying in England and Wales between 1 January 1966 and 31 December 1972. Similar data on deaths assigned to other cancers as the underlying cause were obtained from the samples of death certificates coded for multiple causes by the Registrar-General for England and Wales from all deaths in the same period. The numbers and sources of bladder and other cancer deaths included in the study are shown in Table I. The sources given for the 'other cancers' were determined by the nature of the RegistrarGeneral's samples. These samples were selected randomly from deaths in the whole of England and 
TABLE I

NUMBERS AND SOURCES OF BLADDER CANCER AND OTHER CANCER DEATHS INCLUDED IN THE STUDY (EXCLUDING CANCER OF THE PANCREAS), BY YEAR OF DEATH

\begin{tabular}{|c|c|c|c|c|}
\hline \multirow{2}{*}{$\begin{array}{l}\text { Yoar of } \\
\text { Death }\end{array}$} & \multirow{2}{*}{ Cancer } & \multicolumn{2}{|c|}{ No. of Deaths } & \multirow{2}{*}{ Source of Deaths } \\
\hline & & Men & Women & \\
\hline $1966-67$ & $\begin{array}{l}\text { Bladder } \\
\text { Other }\end{array}$ & $\begin{array}{r}4911 \\
757\end{array}$ & $\begin{array}{r}2008 \\
573\end{array}$ & $\begin{array}{l}\text { All deaths in England and Wales } \\
1 \% \text { at ages } 45-60 \text { years, and } 0.5 \% \\
\text { at ages } 60+\text { years of all deaths in } \\
\text { England and Wales }\end{array}$ \\
\hline $1968-69$ & $\begin{array}{l}\text { Bladder } \\
\text { Other }\end{array}$ & $\begin{array}{r}5200 \\
770\end{array}$ & $\begin{array}{r}2181 \\
611\end{array}$ & $\begin{array}{l}\text { As for } 1966-67 \\
\text { As for } 1966-67\end{array}$ \\
\hline 1970 & $\begin{array}{l}\text { Bladder } \\
\text { Other }\end{array}$ & $\begin{array}{r}239 \\
5351\end{array}$ & $\left.\begin{array}{r}89 \\
4261\end{array}\right\}$ & $\begin{array}{l}\text { All deaths in the Birmingham } \\
\text { Regional Hospital Board area }\end{array}$ \\
\hline 1971 & $\begin{array}{l}\text { Bladder } \\
\text { Other }\end{array}$ & $\begin{array}{r}115 \\
2864\end{array}$ & $\left.\begin{array}{r}44 \\
2340\end{array}\right\}$ & $\begin{array}{l}\text { All deaths in the Oxford } \\
\text { Regional Hospital Board area }\end{array}$ \\
\hline 1972 & $\begin{array}{l}\text { Bladder } \\
\text { Other }\end{array}$ & $\begin{array}{l}2782 \\
5621\end{array}$ & $\begin{array}{l}1166 \\
4906\end{array}$ & $\begin{array}{l}\text { All deaths in England and Wales } \\
10 \% \text { of all deaths in England and Wales }\end{array}$ \\
\hline
\end{tabular}

Wales except in 1970 and 1971 when deaths from only the Birmingham and Oxford regions, respectively were used. The bladder cancer deaths studied from 1970 and 1971 were limited to these regions so that they should come from the same areas as the other cancer deaths. The analyses were restricted to persons aged 45 years and over for convenience in obtaining data from the multiplecause-coded samples; there were, in any case, few individuals under this age dying from bladder cancer during the period of the study and none of them had diabetes mentioned on the death certificate.

Further data were obtained on those of the above patients who had died in 1971 or 1972 and had diabetes mellitus mentioned on the death certificate, to enable us to examine the association between duration of diabetes and risk of bladder cancer. In this part of the study, patients who died from bladder cancer in 1971 were taken from the whole of England and Wales, not just the Oxford region. For each of these patients, inquiries were made of the medical practitioner who signed the death certificate or of the hospital consultant who cared for the patient during his terminal illness, to determine the dates of diagnosis of diabetes mellitus and of the fatal cancer. Where necessary the patient's National Health Service general-practice notes were also obtained, with the general practioner's consent, from the Local Family Practitioner Committee.

\section{SACCharin CONSUmPTION}

Questionnaires were mailed to a random sample of 200 diabetics (112 women and 88 men) currently attending the Radcliffe Infirmary diabetic clinic. This clinic has about 3000 regular attenders and accepts referrals of patients of any degree of severity from general practitioners in Oxford and surrounding $\vec{c}$ areas. Questionnaires were also mailed to $200 \frac{5}{5}$ individually matched control patients who were selected randomly from non-diabetics of the same $\overrightarrow{0}$ sex and within the same 5-year age group current o on the list of the same general practice as the diabetic. If no reply was received, a further question naire was mailed and, if necessary, the patient was visited by a research assistant. The questionnaire covered the present and past use of artificial sweeteners:
in tablet or liquid form
added to food during meal preparation
in already prepared low-calorie foods
in conventional and low-calorie soft drinks.

Questions were also asked regarding the history of diabetes mellitus, body height and weight, occupation, religious affiliation, and smoking habits.

\section{SMOKIng Habits}

Data on the smoking habits of diabetics were obtained from the Boston Collaborative Drug Surveillance Program (Jick et al., 1973), in which nurse monitors obtained information on some 25000 ज consecutive patients aged between 20 and 75 years $\mathrm{N}$ admitted to general medical and surgical wards $\underset{\omega}{N}$ of co-operating Boston hospitals. Shortly after admission, the patients were interviewed regarding smoking and other habits. Diagnoses (up to six per $\frac{}{\mathscr{}}$ patient) were recorded after the patient's discharge? from hospital.

For the purpose of this study, diabetics were 0 defined as patients who were discharged with any diagnosis of diabetes mellitus; all other patients $\mathbb{Q}$ 
were regarded as controls. Non-Caucasian patients and any patient with a first diagnosis of any disease which might have been associated with cigarette smoking were excluded from both groups. The following diseases were excluded:

acute and chronic lung diseases oropharyngeal and respiratory neoplasms cancers of the pancreas, bladder, and kidneys myocardial infarction and all other diseases caused by arteriosclerosis

pulmonary heart disease

peptic ulceration

all alcoholic diagnoses.

This left 984 diabetics, of whom $328(33 \cdot 3 \%)$ had a first diagnosis of diabetes mellitus, and 15692 controls with a wide range of medical and surgical diseases.

Data were also obtained on the relationship between smoking habits and duration of diabetes from patients attending the Radcliffe Infirmary diabetic clinic. Each patient attending over a 13-week period was questioned about smoking habits. In addition, the date of first diagnosis of diabetes mellitus was recorded from the patient's clinic notes.

\section{RESULTS}

\section{Bladder Cancer Mortality}

The observed and expected numbers of patients with both bladder cancer and diabetes mellitus on the death certificate are shown in Table II. The expected numbers of certificates with mention of diabetes were calculated from the pooled observations for bladder and other cancer deaths within each 10-year age group and each calendar year group (Table I). The other cancers included all other types of cancer except cancers of the pancreas and lung, which were excluded because their incidence rates in diabetics were thought to be different from the rates in the general population (Kessler, 1970). These exclusions had very little effect on the expected

TABLB II

OBSER VED AND EXPECTED NUMBERS OF PATIENTS WITH BOTH BLADDER CANCER OR LUNG CANCER AND DIABETES MELLITUS ON THE DEATH CERTIFICATE WITH ALL OTHER CANCERS (EXCLUDING PANCREAS AND LUNG) AS A CONTROL GROUP

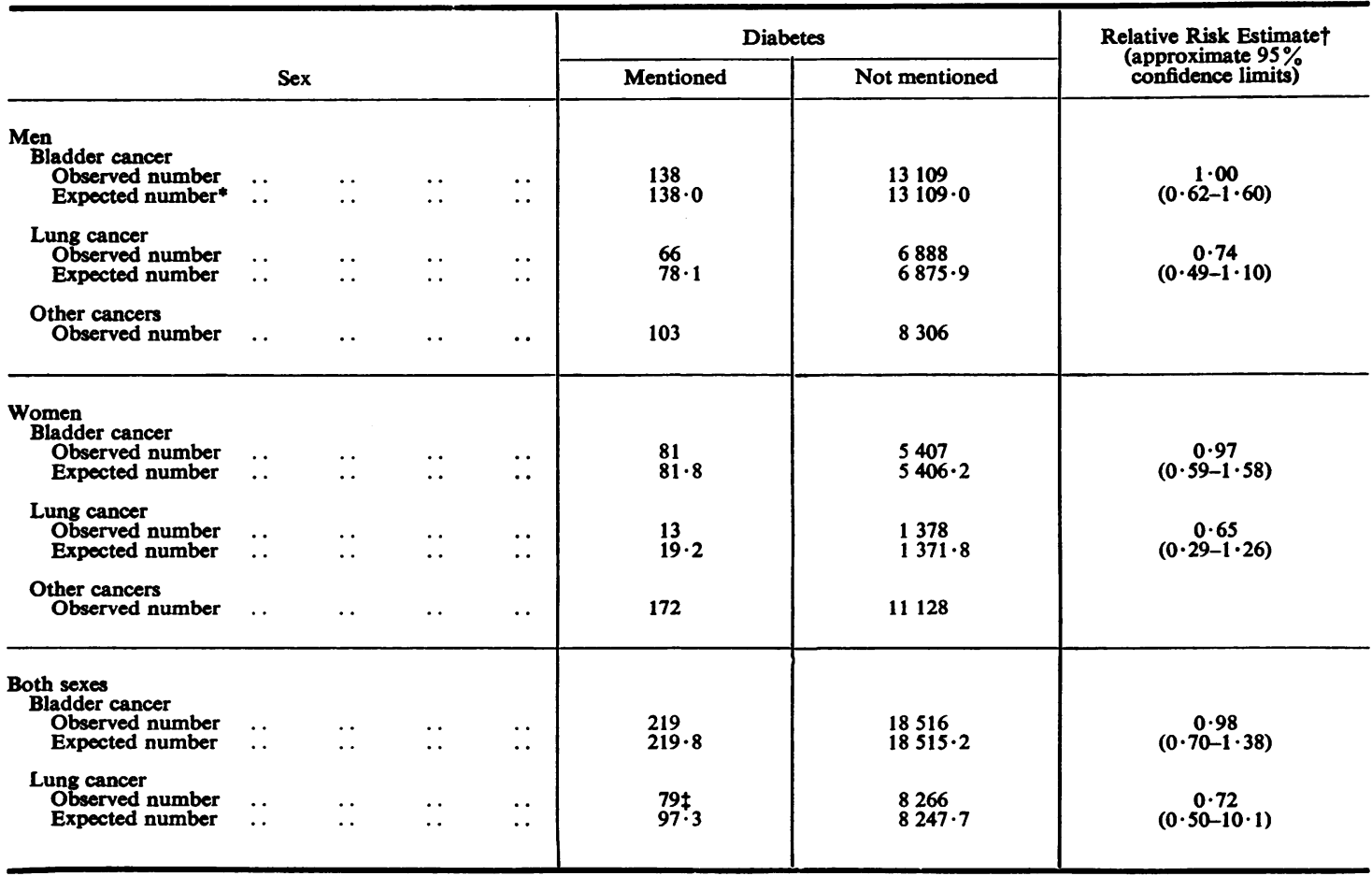

-Expected numbers calculated from the pooled experience of bladder (or lung) cancer and the remaining cancers in each 10-year age group and each calendar year group (Table I)

tEstimated risk of bladder or lung cancer in diabetics relative to risk of unity in non-diabetics

†Observed number different from expected number $P<\cdot 02\left(\chi^{2}=6 \cdot 0\right.$; Mantel and Haenszel, 1959) 
numbers. Also shown are estimates of the relative risk of bladder cancer in patients with diabetes mellitus. The validity of these estimates depends upon the assumption that the proportion of diabetics dying from bladder cancer who have diabetes mentioned on the death certificate is the same as the proportion in diabetics dying from other cancers (about 44\%, Armstrong, unpublished). These data provide no evidence of an increased risk of bladder cancer in diabetics. The best estimate of this risk, relative to that in non-diabetics, is 0.98 to one; it is unlikely to be more than 1.38 to one or less than 0.70 to one. The estimates of the relative risk and their approximate $95 \%$ confidence limits were calculated controlling for age (by decade to 85 years or more) and calendar year of death, using an asymptotic approximation to the maximum likelihood estimate, modified from Miettinen (1970) (Susannah Howard, unpublished).

Table II also shows the observed and expected numbers of patients having both lung cancer and diabetes mentioned on the death certificate with the corresponding estimates of relative risk. The estimate of the relative risk of lung cancer in diabetics of both sexes $(0.72)$ is significantly less than unity.

In view of the possibility that a detectable increase in risk of bladder cancer might appear only after saccharin had been consumed for many years, we sought information about the relationship between the duration of diabetes and the onset of cancer in patients who had died in 1971 and 1972. Of the 269 patients included in this part of the study, complete data could be obtained for 267 (88 patients with bladder cancer and 179 with other cancers). Of these patients, 23 had diabetes and cancer diagnosed simultaneously (10 with bladder and 13 with other cancers) and 38 had diabetes diagnosed after the cancer (13 with bladder and 25 with other cancers); these are not considered further. Observed and expected numbers of bladder cancer patients, subdivided by the duration of diabetes before the diagnosis of cancer, are shown in Table III with all other cancers used as a control group (excluding cancers of the pancreas and lung). There was no excess of long-duration diabetes in bladder cancer patients, and the risk of death from bladder cancer in patients with diabetes of 20 or more years' duration, relative to that in diabetics of less than 20 years' duration, is unlikely to be greater than 1.17 to one for both sexes or 1.73 to one if only men are are considered (relative risk estimates 0.17 for both sexes and 0.21 for men only; $95 \%$ confidence limits $0 \cdot 01-1 \cdot 17$ and $0 \cdot 01-1 \cdot 73$, respectively).
TABLE III

DURATION OF DIABETES BEFORE DIAGNOSIS OF CANCER IN PATIENTS WITH BLADDER CANCER, LUNG CANCER, AND OTHER CANCERS (EXCLUDING LUNG AND PAN: CREAS) AND DIABETES MELLITUS

\begin{tabular}{|c|c|c|c|c|}
\hline \multirow[b]{2}{*}{ Sex } & & \multicolumn{3}{|c|}{ Duration of Diabetes (years) } \\
\hline & & $<10$ & $10-19$ & $20+$ \\
\hline $\begin{array}{l}\text { Men } \\
\text { Bladder cancer } \\
\text { Observed number } \\
\text { Expected number* }\end{array}$ & $\begin{array}{l}\cdots \\
\cdots \\
\cdots\end{array}$ & $34 \cdot 2$ & $\begin{array}{l}9 \\
7 \cdot 5\end{array}$ & $2 \cdot 3$ \\
\hline $\begin{array}{l}\text { Lung cancer } \\
\text { Observed number } \\
\text { Expected number }\end{array}$ & $\therefore$ & $21 \cdot 6$ & $\begin{array}{l}5 \\
4 \cdot 6\end{array}$ & $\begin{array}{l}3 \\
2 \cdot 9\end{array}$ \\
\hline $\begin{array}{l}\text { Other cancers } \\
\text { Observed number }\end{array}$ & .. & 28 & 5 & 5 \\
\hline $\begin{array}{l}\text { Woment } \\
\text { Bladder cancer } \\
\text { Observed number } \\
\text { Expected number }\end{array}$ & $\therefore$ & $\begin{array}{l}12 \\
10.9\end{array}$ & $\begin{array}{l}8 \\
8 \cdot 1\end{array}$ & $\stackrel{0}{1} \cdot 0$ \\
\hline $\begin{array}{l}\text { Other cancers } \\
\text { Observed number }\end{array}$ & .. & 36 & 26 & 8 \\
\hline $\begin{array}{l}\text { Both sexes } \\
\text { Bladder cancer } \\
\text { Observed number } \\
\text { Expected number }\end{array}$ & $\therefore$ & $\begin{array}{l}46 \\
44 \cdot 1\end{array}$ & $\begin{array}{l}17 \\
15 \cdot 6\end{array}$ & 2 \\
\hline
\end{tabular}

*Expected numbers calculated from the pooled experience of bladder $\overrightarrow{0}$ (or lung) cancer and the remaining cancers within each 10-year ag †Figures for lung cancer not given as only 4 observed

\section{SACCharin Consumption}

Replies were received from 112 female (aged 18 to 97, mean $58 \cdot 7$ years) and 85 male diabetics (aged 17 to 80 , mean 56.4 years), and 108 female (aged 15 to 94, mean $57 \cdot 7$ years) and 83 male control patients (aged 18 to 82, mean 56.1 years). Eleven patients refused to reply and one could not be traced.

The percentages of patients consuming saccharin in different forms are shown in Table IV. A significantly higher proportion of both male and female diabetics than of non-diabetics consumed saccharin tablets, saccharin-containing foods, and low-calorie $\delta$ soft drinks. Only a small proportion of patients in all groups used saccharin in the preparation of food. 을 The probability levels in this table are based on values of $x$-squared calculated from data on 80 을 matched male and 108 matched female pairs (Pike and Morrow, 1970).

Data were also obtained on the past use of $N$ saccharin tablets. Of male diabetics, $3.5 \%$ had $\mathrm{N}$ used saccharin tablets in the past but no longer 0 used them, as had $12.5 \%$ of female diabetics, $9.6 \%$ of male non-diabetics, and $6.5 \%$ of female non- $\frac{\bar{D}}{\Phi}$ diabetics. One $(1 \cdot 2 \%)$ male diabetic, five $(4.5 \%) \stackrel{?}{+}$ female diabetics, no male non-diabetics, and four 0 $(3 \cdot 7 \%)$ female non-diabetics had reduced their saccharin consumption as a result of 'publicity' about artificial sweeteners. 
TABLE IV

CURRENT SACCHARIN USE FROM VARIOUS SOURCES IN DIABETIC AND NON-DIABETIC PATIENTS

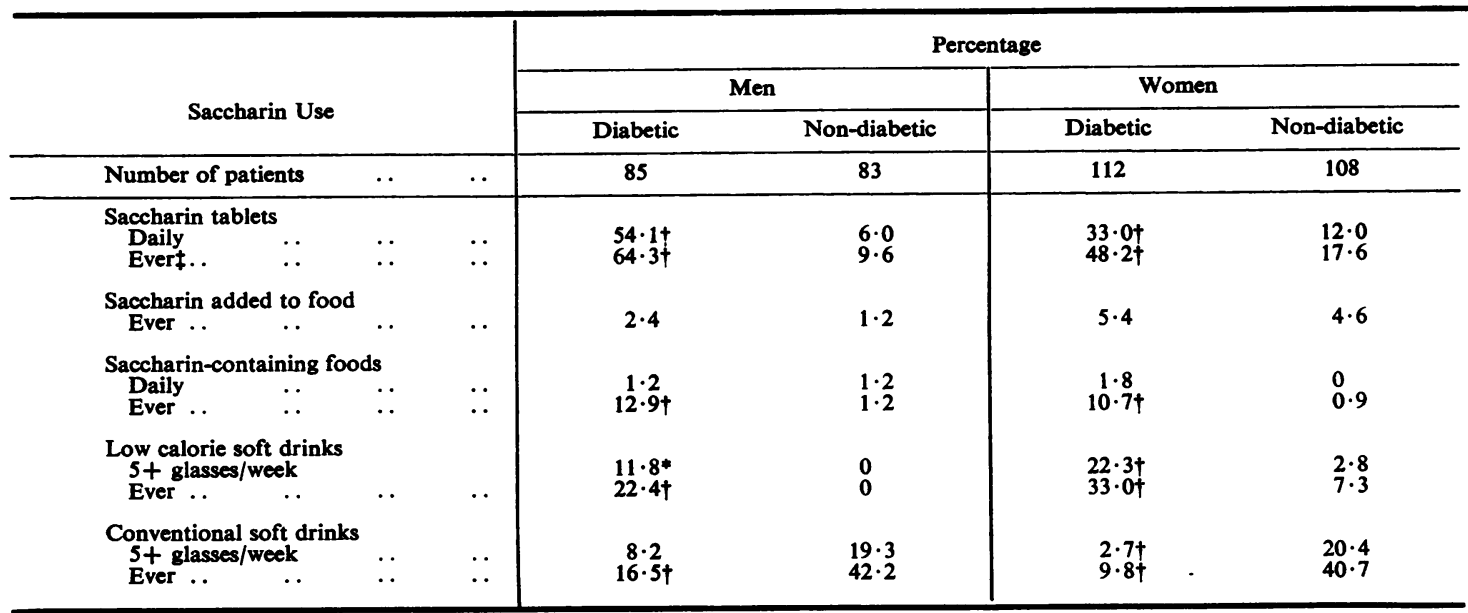

Significance of difference between diabetics and non-diabetics:

$* \mathbf{P}<0.01$

$+\mathrm{P}<0.001$

$\ddagger$ Ever $=$ current use at any frequency

TABLE V

ESTIMATED DAILY SACCHARIN CONSUMPTION FROM TABLETS AND CONVENTIONAL AND LOW-CALORIE SOFT DRINKS

\begin{tabular}{|c|c|c|c|c|c|c|}
\hline & & & \multicolumn{4}{|c|}{ Daily Saccharin Consumption (mg/kg) } \\
\hline \multirow{2}{*}{\multicolumn{3}{|c|}{ Patients }} & \multicolumn{2}{|c|}{ Average } & \multicolumn{2}{|c|}{ Range } \\
\hline & & & Tablets only & Tablets + Soft Drinks & Tablets only & Tablets+Soft Drinks \\
\hline \multicolumn{7}{|l|}{ Men } \\
\hline Diabetic & $(85) \ddagger \ldots$ & . & $1 \cdot 02 \dagger$ & $1 \cdot 26 t$ & $0-5 \cdot 34$ & $0-8 \cdot 42$ \\
\hline Non-diabetic & (82) $\quad$. & .. & 0.05 & 0.09 & $0-1 \cdot 51$ & $0-1 \cdot 58$ \\
\hline \multicolumn{7}{|l|}{ Women } \\
\hline Diabetic & (111) $\ldots$ & .. & $0 \cdot 46^{*}$ & $0.72^{*}$ & $0-6 \cdot 55$ & $0-8.04$ \\
\hline Non-diabetic & (105) $\ldots$ & . & $0 \cdot 22$ & $0 \cdot 30$ & $0-6 \cdot 47$ & $0 \cdot 6 \cdot 47$ \\
\hline
\end{tabular}

Significance of difference between diabetics and non-diabetics (Mann-Whitney $U$ test):

$* \mathrm{P}<0.05$

$+\mathrm{P}<0.001$

$\$$ Numbers in parentheses refer to numbers of patients with sufficient data for estimate

From data on the number of saccharin tablets and glasses of soft drinks currently consumed daily, an estimate was made of the daily saccharin consumption by each individual from these sources. Each tablet was assumed to contain $12.5 \mathrm{mg}$ of saccharin, each glass of low-calorie soft drink $50 \mathrm{mg}$, and each glass of conventional soft drink $10 \mathrm{mg}$. The average and range of saccharin consumption for each group of patients are shown in Table V. Diabetics of either sex consumed significantly more saccharin than did non-diabetics, whereas diabetic men consumed more saccharin than did diabetic women $(\mathrm{P}<0.01)$ and non-diabetic women consumed more saccharin than did non-diabetic men $(\mathrm{P}<0.05)$.

Of the 14 men and 20 women with diabetes of more than 20 years' duration, 10 men (71\%; 95\% confidence limits 40 to $93 \%$ ) and 4 women (20\%; $95 \%$ confidence limits 4 to $44 \%$ ) had also used saccharin tablets daily for more than 20 years. The longest durations of use with the amounts used were: 4 tablets daily for 53 years in a male diabetic; 5 tablets daily for 44 years in a female diabetic; 4 tablets daily for 10 years in a male non-diabetic; 
and 10 tablets daily for 34 years in a female nondiabetic. Among diabetics currently using saccharin tablets daily, the duration of daily use was highly correlated with, and in most cases equal to, the duration of diabetes (correlation coefficient 0.95 for men and 0.93 for women). The data for men are plotted in the Figure.

The daily use of saccharin tablets was examined within each group of patients according to their attitude to their body weight. Patients were classified as concerned about their weight if they considered

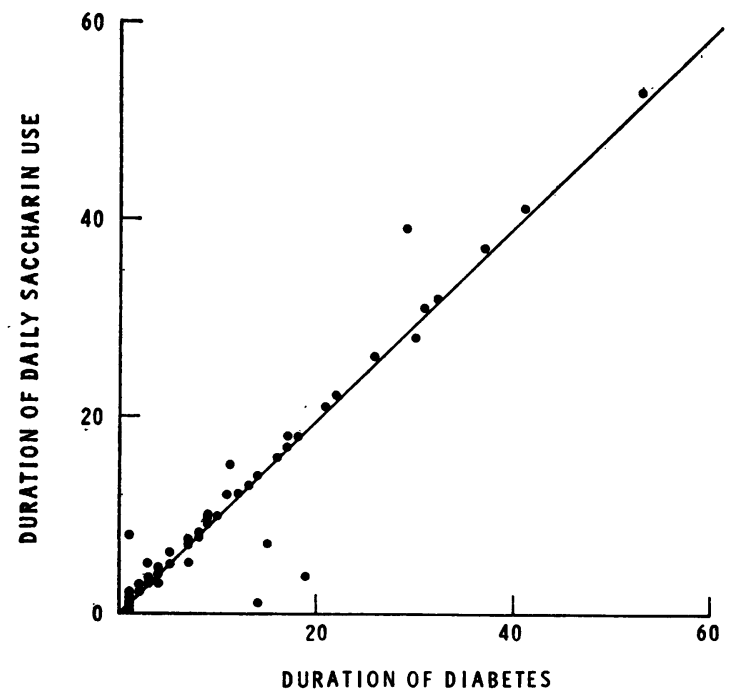

FIGURE. Duration of daily saccharin-tablet use and duration of diabetes mellitus with a fitted regression line $(Y=0.98 X)$ in diabetic men using saccharin tablets daily. themselves to be overweight or if tney were currently dieting or had previously dieted to lose weight. $\frac{\sim}{\Phi}$ Attitude to weight did not appear to influence the? use of saccharin tablets by diabetics or by male $\vec{F}$ non-diabetics, whereas concern about body weight $\frac{\text { ? }}{5}$ was strongly associated with their use in female non-diabetics $\left(19.3 \%\right.$ of those concerned about $\frac{\bar{c}}{\bar{c}}$ their weight used saccharin daily compared with $\overrightarrow{\widetilde{\sigma}}$ $3.9 \%$ of unconcerned; $P<0.05$ ).

Among diabetics, there was no association between the type of diabetic therapy or the strictness with $\vec{\circ}$ which patients said they followed their diabetic diet and saccharin use. The percentage of patients using $\bar{\omega}$ saccharin from any source did not change signifi $\frac{\text {. }}{6}$ cantly with duration of diabetes and was not? associated with age at onset of diabetes.

The distribution of current or pre-retirement occupations was similar in the diabetics and the non-diabetics. There were also no appreciable ${ }_{\rho}^{\omega}$ differences between the smoking habits of diabetics and non-diabetics, but the sample size in this study $\vec{c}$ was insufficient to detect small differences so that data on smoking were sought from another source.

\section{Cigarette Smoking Habits}

The smoking habits of patients included in Boston study are shown in Table VI. The percentages were standardized for age by decades from under 30 years to 70 years or over, using the direct $\frac{0}{\Phi}$ method and the populations of all male or all female diabetics in the study as standards. Age-controlled, summary $\chi$-squared values were calculated for the comparisons of proportions in the various smoking

TABLE VI

AGE-STANDARDIZED PERCENTAGES OF DIABETICS AND NON-DIABETICS IN VARIOUS SMOKING CATEGORIES INŌं BOSTON

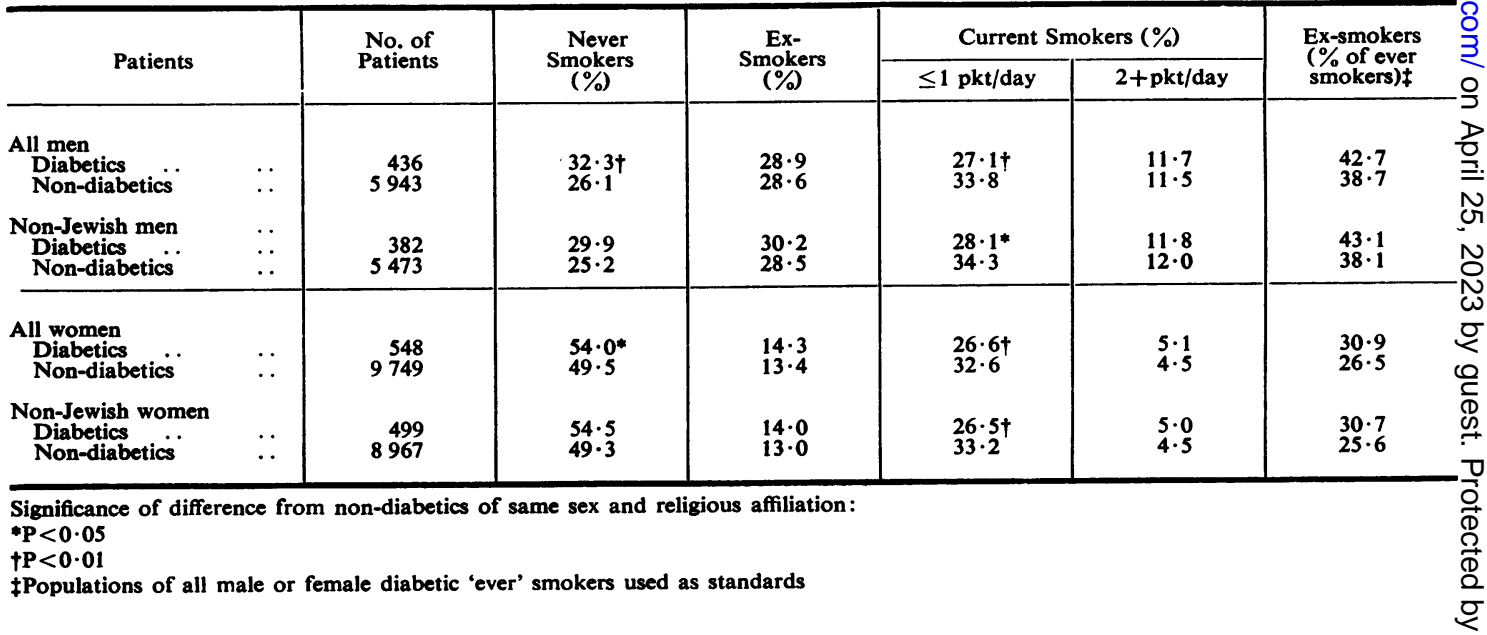


categories (Mantel and Haenszel, 1959) and used to assign the probability levels shown. There was a significant deficit of current smokers of one packet of cigarettes or less per day among both male and female diabetics. These deficits persisted when Jewish patients were excluded and were largely due to an excess of diabetic patients who had never smoked and, less markedly, to an excess of exsmokers. Examination of the age-distribution of these differences showed that they were predominantly in those aged over 60 years.

In view of this difference with age in the Boston data, the smoking habits of 707 patients (345 men and 362 women) attending the Radcliffe Infirmary diabetic clinic were recorded to see whether this was an effect of duration of diabetes. A further 26 patients $(3.5 \%$ of the total approached) attended the clinic during the survey period but refused to be interviewed or were missed by the interviewers. Age-standardized percentages of patients in the various smoking categories are shown in Table VII, subdivided by duration of diabetes. Standardization was performed over 10-year age groups in this case by the indirect method using the overall percentages for each smoking category as the standards. This method was preferred to the direct method because of the very small numbers of patients in some of the age-duration groups. In men, there was a significantly lower proportion of current smokers and correspondingly higher proportion of ex-smokers among diabetics of 20 or more years' duration compared with those of less than 20 years' duration. No such differences were seen in women. Of the 134 male ex-smokers, $48 \%$ had given up smoking before the

TABLE VII

EFFECT OF DURATION OF DIABETES ON THE AGESTANDARDIZED PERCENTAGE OF DIABETICS IN THE VARIOUS SMOKING CATEGORIES IN OXFORD

\begin{tabular}{|c|c|c|c|c|c|}
\hline \multirow[b]{2}{*}{ Patients } & & \multicolumn{4}{|c|}{ Duration of Diabetes (years) } \\
\hline & & $<5$ & $5-9$ & $10-19$ & $20+$ \\
\hline $\begin{array}{l}\text { Men (number) } \\
\text { Never smokers }(\%) \neq \\
\text { Ex-smokers (\%) } \\
\text { Current smokers (\%) } \\
\text { Ex-smokers (as \% of } \\
\text { ever smokers).. }\end{array}$ & $\begin{array}{l}\cdots \\
\cdots \\
\cdots \\
. .\end{array}$ & $\begin{array}{l}127 \\
26 \cdot 3 \\
39 \cdot 8 \\
33 \cdot 9 \\
53 \cdot 3\end{array}$ & $\begin{array}{l}88 \\
28 \cdot 3 \\
31 \cdot 7 \\
39 \cdot 6 \\
43 \cdot 5\end{array}$ & $\begin{array}{l}80 \\
27 \cdot 5 \\
35 \cdot 3 \\
37 \cdot 4 \\
48 \cdot 7\end{array}$ & $\begin{array}{l}50 \\
22 \cdot 8 \\
56 \cdot 9 \dagger \\
18 \cdot 2 * \\
74 \cdot 8 \dagger\end{array}$ \\
\hline $\begin{array}{l}\text { Women (number) } \\
\text { Never smokers }(\%) \\
\text { Ex-smokers (\%) } \\
\text { Current smokers (\%) } \\
\text { Ex-smokers (as \% of } \\
\text { ever smokers).. }\end{array}$ & \begin{tabular}{l|}
$\cdots$ \\
$\cdots$ \\
$\cdots$
\end{tabular} & $\begin{array}{l}117 \\
51 \cdot 7 \\
26 \cdot 3 \\
22 \cdot 0 \\
54 \cdot 9\end{array}$ & $\begin{array}{l}100 \\
48 \cdot 5 \\
22 \cdot 9 \\
28 \cdot 7 \\
42 \cdot 7\end{array}$ & $\begin{array}{l}92 \\
59 \cdot 7 \\
14 \cdot 4 \\
25 \cdot 7 \\
38 \cdot 4\end{array}$ & $\begin{array}{l}53 \\
53 \cdot 1 \\
20 \cdot 4 \\
26 \cdot 5 \\
42 \cdot 6\end{array}$ \\
\hline
\end{tabular}

Significance of difference from diabetics of $<20$ years' duration: *P $<0.05$

$+\mathbf{P}<0.01$

†Some of these percentages do not quite add up to 100 because of the use of the indirect method of standardization onset of diabetes and $8 \%$ gave up in the same year as diabetes was diagnosed; the remainder gave up at varying periods up to more than 20 years after diagnosis.

\section{Discussion}

The validity of this study for determining the relative risk of bladder cancer in diabetics is dependent upon the absence of a difference in the frequency with which diabetes mellitus is detected in patients with different types of cancer (or vice versa), or in the frequency with which diabetes mellitus is recorded on the death certificates of diabetics who die from bladder cancer compared with that in diabetics who die from other cancers. Biases may have been introduced by knowledge of the possible association between artificial sweeteners and bladder cancer, which was first publicized in 1969, and by the fact that patients with bladder cancer would be more likely to have had their urine examined and, perhaps, diabetes diagnosed (and vice versa) than would have patients with other cancers. Both these possible types of bias would, however, have led to an overestimation rather than to an underestimation of the risk of bladder cancer in diabetics.

A more serious problem is the possibleconfounding effect of cigarette smoking on the relationship between bladder cancer and diabetes mellitus. The Boston data (Table VI) suggest that a lower proportion of diabetics smoke cigarettes than do nondiabetics, although the differences between the two groups are small. Using the proportions of current smokers among patients in Boston, it may be estimated that, if the relative risk of bladder cancer in current smokers compared with current nonsmokers is $2 \cdot 0$, only a $4 \%$ reduction in bladder cancer risk (relative risk of 0.96 ) would be expected in diabetics. Although the Boston data cannot necessarily be applied to the population of diabetics in England and Wales, it appears that the confounding effect of smoking habits in this study is unlikely to be large.

If the possible effects of the biases referred to above are ignored, the results of this study suggest that the relative risk of bladder cancer in diabetics is unlikely to be greater than 1.38 in both sexes together or 1.60 if we limit our attention to diabetic men who consume substantially more saccharin than do diabetic women (Table II). The best estimates for the actual relative risks are 1.00 for diabetic men, 0.97 for diabetic women, ard 0.98 for both sexes together. These findings are compatible with Kessler's (1970) study, which showed standardized mortality ratios for bladder cancer in diabetics 
which were not significantly different from 1.0 $(0.77$ in men and 0.61 in women). Our data on saccharin consumption confirm that diabetics, on average, consume substantially more saccharin than do the general population. Even the highest level of consumption, however (approximately $8.42 \mathrm{mg} / \mathrm{kg}$ per day), was only one three-hundredth of the minimum level reported to produce bladder tumours in rats (approximately $2.5 \mathrm{~g} / \mathrm{kg}$ per day).

Because there is usually a long. latent period between initial exposure to a carcinogen and the subsequent development of cancer, it may be that too few diabetics had consumed saccharin for long enough to produce an effect on bladder cancer mortality in the group as a whole. There was no evidence, however, of an increased risk of bladder cancer in patients with diabetes of 20 or more years' duration. If the Oxford data can be applied to the whole of England and Wales, then at least $40 \%$ of the men with diabetes of this duration would have also consumed saccharin tablets daily for more than 20 years.

In this study we have investigated the relationship between saccharin consumption and bladder cancer indirectly, through their common association with diabetes mellitus. A recent investigation has examined the relationship directly by studying the consumption of artificial sweeteners in patients with bladder cancer and matched controls (Morgan and Jain, 1974). These workers also found no positive association between artificial sweeteners and bladder cancer, and perhaps a negative association in women (estimated relative risk 0.35 ). Their results are difficult to interpret, however, as the response rates of both patients and controls were low $(69 \%$ and $57 \%$ respectively) and the control series was limited to men and women with single diseases which might have affected the use of saccharin (men with benign prostatic hypertrophy and women with stress incontinence).

A secondary result of our study is the confirmation of Kessler's (1970) finding of a lower risk of lung cancer among diabetics. It seems likely that this difference is due, at least in part, to the lower proportion of smokers among diabetics. Kessler suggested that the lower risk which he observed in diabetics in Boston may have been due to the high proportion of Jews. This would be unlikely to account for such a difference in England and Wales (none of the 197 Oxford diabetics studied was Jewish) and the smoking habit differences between diabetics and non-diabetics persisted when only non-Jews were examined (Table VI). If we assume a relative risk of $\mathbf{1 0}$ for lung cancer in smokers compared with non-smokers, it may be estimated that the difference in smoking habits between diabetics and non-diabetics might account for a $12 \%$ reduction in lung cancer risk in diabetic men and an? $11 \%$ reduction in diabetic women. Although these $\overrightarrow{\vec{F}}$ estimates are smaller than the observed reductions $(26 \%$ and $35 \%)$ in this study, they fall well within their $95 \%$ confidence limits.

The lower prevalence of current smokers among $\frac{\bar{\phi}}{\vec{\phi}}$ diabetics in Boston may be of some interest. The $\propto$ excess of diabetic 'never' smokers suggests eitheros that non-smokers are more prone to develop diabetes $\overrightarrow{0}$ than are smokers, or that the selective advantages in favour of survival of non-smoking diabetics are $\vec{\omega}$ greater than for the survival of non-smokers in $\frac{\mathscr{\sigma}}{\bar{\phi}}$ general. Paffenbarger and Wing (1973) did not find $\stackrel{\circ}{-}$ that cigarette smoking protected against the develop-iv ment of maturity-onset diabetes, whereas data from ${ }_{i \sim}^{\bullet}$ the Framingham study (Kannel and Gordon, 1973) suggest a synergistic effect of cigarette smoking and ${ }_{\circ}^{\mathrm{C}}$ glucose intolerance in the production of ischaemic ${ }^{-}$ heart disease. Such an effect would give non-smoking $\vec{c}$ diabetics a selective advantage for survival over smoking diabetics which would be in excess of that ${ }^{\Phi}$ experienced by non-smokers over smokers in the $\overrightarrow{0}$ general population. In our data, however, theur proportion of 'never' smokers among diabetics dedo not increase with duration of diabetes (Table VI The proportion of ex-smokers did increase with duration of diabetes, but this could be explained equally well as an effect of pressure from attending $\stackrel{\odot}{\odot}$ physicians to stop smoking as by selective mortality $\overrightarrow{\vec{F}}$ from continuing smoking.

In this study we have been unable to find evidence of an increased risk of bladder cancer in diabetics, some of whom must have consumed above average amounts of saccharin for more than 20 years. We should, of course, not have found an excess risk of ${ }_{\sigma}^{-}$ bladder cancer if saccharin were equally carcinogenic 3 . for other organs as for the bladder because the control patients were patients with other cancers. This,, however, seems rather unlikely. Certainly, the animal data do not suggest that saccharin has $a_{\supset}^{J}$ general carcinogenic effect in all sites. Our data음. cannot exclude the possibility of a weak carcinogenic effect of saccharin upon the human bladder, but no ${ }^{\text {G }}$ data can be expected to do this unless the agent 0

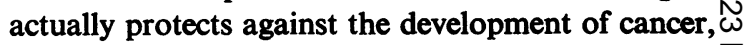
as it is impossible to prove a negative. So far as they go, the data are reassuring and encourage the belief that saccharin is not carcinogenic to man in the amounts commonly used by diabetics.

We are most grateful to Mr Richard Peto and Professoro Martin Vessey for their advice in all aspects of this study; $: \vec{Q}$ 
to the Registrar-General for the sample of multiplecause-coded death certificates, and to Dr A. Adelstein and Dr. J. Donovan for their assistance with them; to Mrs P. Clark, Miss P. Lawrie, and Mrs D. McClelland for their assistance in the collection and preparation of the data; to Dr Joan Davies of the Royal Marsden Hospital for making the bladder cancer death certificates available to us; to Dr Hershel Jick, Dr Samuel Shapiro, and Dr Stuart Hartz for making available and assisting with data from the Boston Collaborative Drug Surveillance Program; to Dr E. Cliffe and Mr G. Turnbull of Boots Co. Ltd. for providing data on the saccharin content of foods and soft drinks; to Dr Derek Hockaday for allowing us to approach patients of the Radcliffe Infirmary Diabetic Clinic; and to the many general practitioners and consultants who assisted in inquiries regarding their patients.

Bruce Armstrong was supported by an F. A. Hadley Scholarship of the University of Western Australia and a Clinical Sciences Fellowship in Epidemiology of the National Health and Medical Research Council of Australia; the work was supported by a grant from the Department of Health and Social Security.

Requests for reprints: Professor Sir Richard Doll, FRCP FRS, Regius Professor of Medicine, Radcliffe Infirmary, Oxford OX2 6HE.

\section{REFERENCES}

Allen, M. J., Boyland, E., Dukes, C. E., Horning, E. S., and Watson, J. G. (1957). Cancer of the urinary bladder induced in mice with metabolites of aromatic amines and tryptophan. Brit. J Cancer. 11, 212.

ARmStrong, B. and Doll, R. (1974). Bladder cancer mortality in England and Wales in relation to cigarette smoking and saccharin consumption. Brit. J. prev. soc. Med., 28, 233.

BERINGer, Von A. (1973). Ist die Anwendung der Süssstoffe bei Diabetikern gefährlich? Wien med.. Wschr., 123, 41.

BIBRA Information Bulletin (1973). Editorial: Saccharin -a European assessment. 12, 274.

Cole, P., Monson, R. R., Haning, H., and Friedell, G. H. (1971). Smoking and cancer of the lower urinary tract. New Engl. J. Med., 284, 129.
Doll, R. (1972). Cancers related to smoking. In: The Second World Conference on Smoking and Health, edited by R. G. Richardson, p. 10. Isaac Pitman, London.

Hicks, R. M., Wakefield, J. St. J., and Chowaniec, J. (1973). Co-carcinogenic action of saccharin in the chemical induction of bladder cancer. Nature (Lond.), 243, 347.

Jick, H., Miettinen, O. S., Neff, R. K., Shapiro, S., HeInonen, O. P., and Slone, D. (1973). Coffee and myocardial infarction. New Engl. J. Med., 289, 63.

KanNel, W. B. and GoRdon, T. (1973). Assessment of coronary vulnerability-The Framingham Study. In: Skandia International Symposia. Early phases of coronary heart disease, edited by J. Waldenström, T. Larsson, and N. Ljungstedt, p. 123. Nordiska, Bokhandelns Förlag, Stockholm.

KESSLER, I. I. (1970). Cancer mortality among diabetics. J. nat. Cancer Inst., 44, 673.

Lockwoon, K. (1961). On the etiology of bladder tumors in København-Frederiksberg. Acta path. microbiol. scand., 51, Suppl. No. 145.

Mantel, N. and Haenszel, W. (1959). Statistical aspects of the analysis of data from retrospective studies of disease. J. nat. Cancer Inst., 22, 719.

Mietrinen, O. S. (1970). Estimation of relative risk from individually matched series. Biometrics, $26,75$.

MoRgan, R. W. and JAIN, M. G. (1974). Bladder cancer, smoking, beverages and artificial sweeteners. Canad. med. Ass. J., 111, 1067.

Paffenbarger, R. S. and Wing, A. L. (1973). Chronic disease in former college students. XII. Early precursors of adult-onset diabetes mellitus. Amer. J. Epidem., 97, 314.

PIKe, M. C. and Morrow, R. H. (1970). Statistical analysis of patient-control studies in epidemiology. Factor under investigation an all-or-none variable. Brit. J. prev. soc. Med., 24, 42. 